\title{
Factors to consider for surgical in elderly patients with oral cancer
}

\author{
Sung-Tak Lee, Jin-Wook Kim \\ Department of Oral and Maxillofacial Surgery, School of Dentistry, Kyungpook National University, Daegu, Korea
}

\begin{abstract}
J Korean Assoc Oral Maxillofac Surg 2021;47:388-393)
At present, in Korea, due to developments in medicine and technology and an increasing mean lifespan, the expected lifetime for elderly people is increasing (at 70 years, the expected additional lifespan is 14.8 years for males and 18.3 years for females). However, among all causes of death, malignant neoplasm is ranked first for all ages. Further, the incidence rate of oral cancer tends to increase with age. Thus, oral and maxillofacial surgeons have increased opportunity to experience the 'oldest old' patients with oral cancer. Elderly patients commonly have several comorbidities, poor general condition, limited socioeconomic support, fear of various postoperative complications, and perception of short for the rest of their life. In this situation, the patient, caregiver, and surgeon often choose undergraded treatment rather than standard treatment for oral squamous cell carcinoma owing to patient age. In elderly patients with oral cancer, ablation of tumor or reconstructive surgery is challenging for surgeons. Oral and maxillofacial surgeons must evaluate carefully the patient's medical condition and make a decision regarding treatment plans after sufficient discussion with patient and caregivers. We review the literature to consider the factors involved for deciding on a treatment plan regarding surgery in elderly patients with oral cancer.
\end{abstract}

Key words: Oral cancer, Surgery, Elderly patients

[paper submitted 2020. 9. 9 / revised 2020. 12. 1 / accepted 2020. 12. 1]

\section{Introduction}

According to the KOSIS (Korean Statistical Information Service) ${ }^{1}$, of all the causes of death, malignant neoplasm ranked first in all age groups in 2018. The death rate related to malignant neoplasms is higher in older individuals, especially among those aged $>50$ years. The incidence rate of oral cancer in those older than 70 years was $22.05 / 100,000$, while that of oral cancer in all age groups was 7.2/100,000. Compared with the data from 10 years previous, the incidence rate has increased, meaning that there is higher physician likelihood of experiencing oral cancer in patients aged $>70$ years.

Although there is an increase in number of elderly patients with oral cancer, appropriate management of elderly patients remains relatively controversial. Elderly patients commonly

\footnotetext{
Jin-Wook Kim

Department of Oral and Maxillofacial Surgery, School of Dentistry, Kyungpook National University, 2177 Dalgubeol-daero, Jung-gu, Daegu 41940, Korea

TEL: +82-53-600-7550

E-mail:vocaleo@knu.ac.kr

ORCID: https://orcid.org/0000-0003-4074-877X
}

(c) This is an open-access article distributed under the terms of the Creative Commons Attribution Non-Commercial License (http://creativecommons.org/ licenses/by-nc/4.0/), which permits unrestricted non-commercial use, distribution, and reproduction in any medium, provided the original work is properly cited.

Copyright (C) 2021 The Korean Association of Oral and Maxillofacial Surgeons. have several comorbidities, poor general condition, limited socioeconomic support, fear of various postoperative complications, and perception of short for the rest of their life. These factors can interfere with the physician's decision on surgery ${ }^{2,3}$. The ability to reconstruct with a free flap also can affect the decision for surgery ${ }^{4}$. In fact, in the clinical setting, these factors can degrade the pre-therapeutic evaluation and management of oral cancer in elderly patients.

We present the following review of the factors included in the decision for surgery in elderly patients with oral cancer.

\section{Age and Performance Status}

Oral cancer, especially oral squamous cell carcinoma (OSCC), is common in age groups in their $60 \mathrm{~s}$ and $80 \mathrm{~s}^{5}$. In Korea, the incidence rate of oral cancer (including lip, oral cavity, and pharynx) has increased considerably in those aged $>50$ years; further, the incidence rate in those aged $>70$ years is approximately 1.5 times higher than in those aged 50-60 years ${ }^{6}$.(Fig. 1)

At present, in Korea, having reached the age of 70 years, the expected further lifespan is 14.8 years for males and 18.3 years for females. Thus, oral or head and neck cancer (HNC) clinicians can face 'oldest old' patients (aged $>85$ years) with 


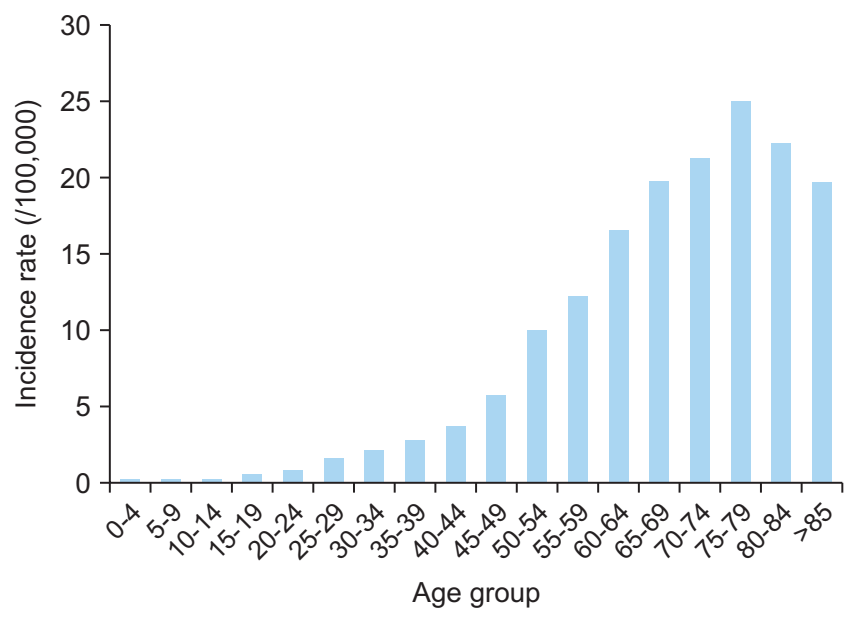

Fig. 1. Cancer incidence rate by age group in Korea, 2016 (KOSIS [Korean Statistical Information Service]).

Sung-Tak Lee et al: Factors to consider for surgical in elderly patients with oral cancer. $J$ Korean Assoc Oral Maxillofac Surg 2021

oral cancer ${ }^{7}$. In this situation, sometimes clinicians choose undergraded treatment rather than standard treatment for OSCC owing to patient age ${ }^{8,9}$.

Gambotti et al. ${ }^{10}$ reported that 59 of 125 OSCC patients aged $>70$ years in a retrospective study received standard treatment including surgical removal of the tumor and neck or associated post-operative irradiation if needed in patients in advanced stages or those with margin involvement. In this study, the independent factors for poor prognosis were age $>80$ years, $\geq \mathrm{T} 1$ stage, and substandard surgery. In other studies, the main reported poor prognosis factors were comorbidities and $\mathrm{T}$ stage $\mathrm{e}^{11-13}$. The authors in the present study suggest that in this population that was treated curatively, there was no significant difference in the survival curves of patients who received standard treatment compared to those who underwent substandard treatment. There was a significant difference when the data were adjusted for age and $\mathrm{T}$ stage.

On the other hand, Wu et al. ${ }^{14}$ reported a study on surgical treatment for $\mathrm{HNC}$ among those aged $>65$ years and showed that 637 patients received surgical treatment and presented no significant difference in postoperative complications, including death, among the following age groups: 65-74 years, considered "young-old"; 75-85 years, considered "older-old"; and $>85$ years, considered "oldest-old". Diabetes was associated with systemic complications, surgical complications, and wound healing problems. However, these associations were not significantly different between the age groups. Wu et al. ${ }^{14}$ concluded that patient age might not be a risk factor in surgical treatment of HNC in elderly patients, and that age was not a risk factor for flap reconstruction. Treatment should be based on medical assessment and patient preferences rather than patient age ${ }^{14}$.

Many authors have suggested that medical conditions such as diabetes, cardiovascular disease, and pulmonary disease are risk factors for surgery in older patients rather than age itself ${ }^{14-16}$. The presence of comorbidities in elderly patients is a key indicator against surgery because comorbidities increase the risk of postoperative complications. Thus, it is crucial to evaluate accurately the preoperative status of elderly patients to prevent postoperative complications and poor outcomes. Some studies have reported that the presence of comorbidities in elderly patients with $\mathrm{HNC}$ is significantly related to postoperative complications ${ }^{13,17}$.

Chen et al. ${ }^{18}$ reported that, although patient age can influence treatment decisions for oral cancer, age alone might not be the most important consideration; preoperative comorbidity evaluation using Eastern Cooperative Oncology Group (ECOG) performance status and head and neck Charlson comorbidity index (HN-CCI) scores can be helpful in evaluation of elderly patient candidacy for adjuvant therapy and in decisions regarding clinical trial design ${ }^{18}$.

For measuring comorbid disease status, Charlson comorbidity index (CCI) is used in patients with different types of cancer $^{19-21}$. The CCI is the method of scoring for comorbid conditions that might alter the risk of mortality ${ }^{22}$. The index considers 19 comorbid conditions including cardiovascular disease, diabetes mellitus, liver disease, and pulmonary disease. The CCI scoring system comprises many evaluation factors; therefore, some studies have suggested the use of a modified or weighted CCI scoring system in treatment for various types of cancer ${ }^{23-25}$. HN-CCI, a simplified CCI, is composed of six identified conditions that contribute to overall survival and enables evaluation of preoperative performance status to facilitate a decision regarding the treatment plan in elderly patients with oral cancer ${ }^{18,26}$.(Table 1)

In addition to CCI, various performance status systems exist: Adult Comorbidity Evaluation-27 (ACE-27), Karnofsky performance index, American Society of Anesthesiologists (ASA) classification of physical status, and ECOG performance status ${ }^{13,17,27-29}$.(Table 2) Hazard ratio (HR) for overall survival will be 4.26 when ECOG score is higher than $2^{18}$. Bøje et al. ${ }^{26}$ reported that HR was almost 2 at $\mathrm{CCI} \geq 2$.

It is clear that old age is not an independent determinant of eligibility for limited or extensive surgical treatment; careful preoperative evaluation of comorbidities and appropriate perioperative management are necessary. 
Table 1. Charlson comorbidity index $(\mathrm{CCl})$ and head and neck $\mathrm{CCl}(\mathrm{HN}-\mathrm{CCl})$ scores

\begin{tabular}{lcl}
\hline \multicolumn{1}{c}{ CCI } & Score & \multicolumn{1}{c}{ HN-CCI } \\
\hline Prior myocardial infarction & 1 & \\
Congestive heart failure & 1 & Congestive heart failure \\
Peripheral vascular disease & 1 & \\
Cerebrovascular disease & 1 & Cerebrovascular disease \\
Dementia & 1 & \\
Chronic pulmonary disease & 1 & Chronic obstructive \\
& & pulmonary disease \\
Rheumatologic disease & 1 & \\
Peptic ulcer disease & 1 & Peptic ulcer disease \\
Mild liver disease & 1 & Liver disease \\
Diabetes & 1 & Diabetes \\
Cerebrovascular (hemiplegia) & 2 & \\
$\quad$ event & & \\
Moderate-to-severe renal & 2 & \\
disease & & \\
Diabetes with chronic & 2 & \\
complications & & \\
Cancer without metastasis & 2 & \\
Leukemia & 2 & \\
Lymphoma & 2 & \\
Moderate or severe liver & 3 & \\
disease & \\
Metastatic solid tumor & 6 & \\
Acquired immune-deficiency \\
syndrome (AIDS)
\end{tabular}

Sung-Tak Lee et al: Factors to consider for surgical in elderly patients with oral cancer. J Korean Assoc Oral Maxillofac Surg 2021

\section{TNM Stage}

Chen et al. ${ }^{18}$ reported clinical outcomes of OSCC in elderly patients (aged $>70$ years), with prevalence as follows: stage I, 29\%; stage II, 27\%; stage III, 18\%; and stage IV, 34\%. T3/T4 or N2 stage have a higher HR than do lower stages. Gambotti et al. ${ }^{10}$ reported that the prevalence of stage I was $16.8 \%$, that of stage II was $15.2 \%$, that of stage III was $12 \%$, and that of stage IV was $56 \%$ in 125 OSCC patients aged $>70$ years. Twelve of 42 (29\%) clinically staged N0 patients had positive neck node compared to percentages of $43 \%$ for T2 (6/14), 67\% for T3 (2/3), and 20\% for T4 (4/20). Stage $\mathrm{T} 2 / 3 / 4(\mathrm{HR}=3.0)$ patients had significantly different survival prognosis than stage T1 patients. Substandard surgery affected survival prognosis (odds ratio $[\mathrm{OR}]=1.8, P=0.03$ ). The $\mathrm{OR}$ of postoperative complications in stage T3/T4 was 4.3 times higher than in stage T1/T2 $(P=0.02)$, and that of N-positive stage was 6.9 times higher than N0 stage $(P=0.001)^{10}$.

Leu et al. ${ }^{30}$ compared the survival rates of elderly and younger patients by stage of OSCC. The overall and diseasefree survival rates showed a tendency to decrease with more advanced stages of OSCC. There were no statistically significant differences between younger and older patients for any stage except IVA. The authors posited that this phenomenon
Table 2. Eastern Cooperative Oncology Group (ECOG) performance status $^{29}$

\begin{tabular}{|c|c|}
\hline Grade & ECOG performance status \\
\hline 0 & $\begin{array}{l}\text { Fully active, able to carry on all pre-disease performance } \\
\text { without restriction }\end{array}$ \\
\hline 1 & $\begin{array}{l}\text { Restricted in physically strenuous activity but ambulatory } \\
\text { and able to carry out work of a light or sedentary nature, } \\
\text { e.g., light house work, office work }\end{array}$ \\
\hline 2 & $\begin{array}{l}\text { Ambulatory and capable of all selfcare but unable to } \\
\text { carry out any work activities; up and about more than } \\
50 \% \text { of waking hours }\end{array}$ \\
\hline 3 & $\begin{array}{l}\text { Capable of only limited selfcare; confined to bed or chair } \\
\text { more than } 50 \% \text { of waking hours }\end{array}$ \\
\hline 4 & $\begin{array}{l}\text { Completely disabled; cannot carry on any selfcare; totally } \\
\text { confined to bed or chair }\end{array}$ \\
\hline 5 & Dead \\
\hline
\end{tabular}

resulted from suboptimal management based on multiple considerations regarding patient condition, performance status, and choices of families and doctors.

It is well known that patients with advanced $\mathrm{T}$ stage or $\mathrm{N}$ positive stage of OSCC have a worse prognosis. However, in older patients, the main risk factor correlated to outcomes of treatment such as post-operative prognosis and overall survival rate was not patient age but status of cancer. Many authors recommend that elderly patients receive standard therapeutic treatments according to stage of OSCC after proper evaluation and monitoring ${ }^{10,13,18,30}$.

\section{Reconstructive Surgery}

Free flap reconstruction has become the preferred method for repair of large defects in oral cancer surgery. This reconstruction method using microsurgery has several advantages including a two-person approach, best-adapted tissue selection for defective tissue, cosmetic and functional outcomes, and three-dimensional freedom for flap positioning. However, owing to decreased cardiac, respiratory, renal, and immunologic function with age, surgical reconstruction can increase postoperative complications and mortality rates. Therefore, this kind of surgery has been challenging.

Ferrari et al. ${ }^{31}$ compared patients aged $<75$ years with those aged $>75$ years who underwent free flap reconstruction surgery for HNC. Following free flap reconstruction, they reported a survival rate of $98.2 \%$ in the older group and found no significant difference between younger and older patients in terms of postoperative complications. However, the authors preferred soft tissue free flap to bone tissue free flap because of the shorter operation times and the lower morbidity 
in older patients ${ }^{31}$.

Free flap reconstruction after ablation surgery for $\mathrm{HNC}$ in the elderly puts a lot of pressure on surgeons because of the postoperative morbidities. Tsai et al. ${ }^{32}$ studied postoperative morbidity following microsurgical free flap reconstruction in elderly patients. They evaluated 167 patients aged $>65$ years divided into two groups of younger (aged 65-70 years) and older (aged $>70$ years). Infection at the recipient site occurred more frequently in the older group than in the younger group ( $40.4 \%$ vs $19.1 \%, P=0.003$ ). There was no significant difference between the two groups in rate of flap loss. Surgical complication rates were higher in the older group (43.6 vs $19.1 \%, P<0.001)$. The authors further showed that the older group had a significantly higher rate of unplanned postoperative reintubation than the younger group $(P<0.001)$. The older group also had a higher rate of postoperative pulmonary complications $(P<0.004)$. They recommended that prophylactic tracheostomy be carefully assessed for patients aged $\geq 70$ years and wrote that intraoperative blood loss $>220 \mathrm{~mL}$ is an important predictor of postoperative morbidity.

Regarding the method used for flap reconstruction, the use of pedicle or free flap is not related directly to the oncological outcome. Long operation time can influence the occurrence of postoperative complications ${ }^{33,34}$. Wu et al. ${ }^{14}$ stated that a pedicle flap is used more frequently in elderly patients because the reconstruction surgery requires a shorter operation time than free flap surgery. However, patient-related factors such as quality of life should be considered when reconstruction method is selected for patients aged $>65$ years.

Thus, reconstruction surgery can be performed for elderly patients. However, surgeons must carefully choose the method of surgical reconstruction with consideration of patient age and medical status, operative time, and possible postoperative complications, including unexpected reintubation.

\section{Patient Decision}

Some elderly patients with oral cancer choose a substandard or degraded management modality, especially with surgical treatment ${ }^{8,10,35}$. The major reasons are the small number of remaining life years expected and fear of decreased quality of life as indicated by functional loss of speech and mastication after surgical treatment. Patients choose conservative or palliative management owing to reasons such as "How do I live with disabilities at this age?" and "I don't want to have any surgery."

During the decision-making process that involves patient and caregivers, the surgeons must provide detailed information about the expected advantages and disadvantages of surgery, including ablation and reconstructive surgery. If an elderly patient has advanced stage OSCC, the surgeon must inform them of possible poor prognosis and shorter survival rate than a younger patient $t^{10,18,30,36}$. It is necessary to inform the patient that various comorbidities, alcohol consumption, and smoking habit are risk factors for postoperative complications $^{2,10,18,37}$. Surgeons must remember that the decisions regarding management and treatment of cancer are a very important matter not only for the patient, but also for the caregivers. Thus, it is important to respect their choice even when it entails substandard or degraded management.

\section{Vl. Conclusion}

In elderly patients with oral cavity or HNC, patient age does not appear to be an independent determining factor for choosing ablation or immediate reconstruction surgery when the patients' medical status is acceptable. Oral and maxillofacial surgeons must carefully evaluate the patient's medical condition in consultation with medical expects from other fields of medicine. Furthermore, surgeons must make a decision regarding treatment plan after sufficient discussion with patient and caregivers about patient status (age, cancer stage, medical condition, and patient wishes). Expected outcomes with or without surgery must be discussed.

\section{ORCID}

Sung-Tak Lee, https://orcid.org/0000-0001-6651-8046

Jin-Wook Kim, https://orcid.org/0000-0003-4074-877X

\section{Authors' Contributions}

S.T.L. participated in wrote the manuscript and J.W.K. participated in the study design, data collection, and statistical analysis.

\section{Conflict of Interest}

No potential conflict of interest relevant to this article was reported.

\section{References}

1. KKOSIS (Korean Statistical Information Service). Death rates for 
the 10 leading causes of death by age [Internet]. Daejeon: Statistics Korea [cited 2020 Aug 1]. Available from: https://kosis.kr/publication/publicationThema.do

2. Bøje CR, Dalton SO, Grønborg TK, Primdahl H, Kristensen CA, Andersen E, et al. The impact of comorbidity on outcome in 12 623 Danish head and neck cancer patients: a population based study from the DAHANCA database. Acta Oncol 2013;52:285-93. https://doi.org/10.3109/0284186X.2012.742964

3. Chen RC, Royce TJ, Extermann M, Reeve BB. Impact of age and comorbidity on treatment and outcomes in elderly cancer patients. Semin Radiat Oncol 2012;22:265-71. https://doi.org/10.1016/ j.semradonc.2012.05.002

4. Fang QG, Shi S, Li M, Zhang X, Liu FY, Sun CF. Free flap reconstruction versus non-free flap reconstruction in treating elderly patients with advanced oral cancer. J Oral Maxillofac Surg 2014;72:1420-4. https://doi.org/10.1016/j.joms.2014.01.010

5. Sasaki T, Moles DR, Imai Y, Speight PM. Clinico-pathological features of squamous cell carcinoma of the oral cavity in patients $<40$ years of age. J Oral Pathol Med 2005;34:129-33. https://doi. org/10.1111/j.1600-0714.2004.00291.x

6. KOSIS (Korean Statistical Information Service). Cancer incident cases and incidence rates by site (24 items), sex, age group [Internet]. Daejeon: Statistics Korea [cited 2020 Aug 1]. Available from: http://kosis.kr/statHtml/statHtml.do?orgId=117\&tblId=DT_117N_ A00023\&conn_path $=$ I3

7. Parker SL, Tong T, Bolden S, Wingo PA. Cancer statistics, 1997. CA Cancer J Clin 1997;47:5-27. https://doi.org/10.3322/canjclin.47.1.5

8. Fentiman IS. Are the elderly receiving appropriate treatment for cancer? Ann Oncol 1996;7:657-8. https://doi.org/10.1093/oxfordjournals.annonc.a010712

9. Clayman GL, Eicher SA, Sicard MW, Razmpa E, Goepfert H. Surgical outcomes in head and neck cancer patients 80 years of age and older. Head Neck 1998;20:216-23. https://doi.org/10.1002/ (sici)1097-0347(199805)20:3<216::aid-hed6>3.0.co;2-3

10. Gambotti L, Schwob E, Schouman T, Murcier G, Goudot P, Mallet A, et al. Are elderly patients presenting with squamous cell carcinoma of the oral cavity given the appropriate treatment? Surg Oncol 2018;27:715-21. https://doi.org/10.1016/j.suronc.2018.04.005

11. Piccirillo JF, Vlahiotis A. Comorbidity in patients with cancer of the head and neck: prevalence and impact on treatment and prognosis. Curr Oncol Rep 2006;8:123-9. https://doi.org/10.1007/s11912006-0047-z

12. Reid BC, Alberg AJ, Klassen AC, Samet JM, Rozier RG, Garcia I, et al. Comorbidity and survival of elderly head and neck carcinoma patients. Cancer 2001;92:2109-16. https://doi.org/10.1002/10970142(20011015)92:8<2109::aid-cncr1552>3.0.co;2-m

13. Sanabria A, Carvalho AL, Vartanian JG, Magrin J, Ikeda MK, Kowalski LP. Comorbidity is a prognostic factor in elderly patients with head and neck cancer. Ann Surg Oncol 2007;14:1449-57. https://doi.org/10.1245/s10434-006-9296-1

14. Wu Y, Zhang B, Huang Z, Ruan Y, Huang Z. Study of surgical treatment for elderly patients with head and neck cancer. Int J Oral Maxillofac Surg 2018;47:824-9. https://doi.org/10.1016/ j.ijom.2018.01.018

15. Piccirillo JF, Tierney RM, Costas I, Grove L, Spitznagel EL Jr. Prognostic importance of comorbidity in a hospital-based cancer registry. JAMA 2004;291:2441-7. https://doi.org/10.1001/ jama.291.20.2441

16. Ferrier MB, Spuesens EB, Le Cessie S, Baatenburg de Jong RJ. Comorbidity as a major risk factor for mortality and complications in head and neck surgery. Arch Otolaryngol Head Neck Surg 2005;131:27-32. https://doi.org/10.1001/archotol.131.1.27

17. Derks W, De Leeuw JR, Hordijk GJ, Winnubst JA. Elderly patients with head and neck cancer: short-term effects of surgical treatment on quality of life. Clin Otolaryngol Allied Sci 2003;28:399-405. https://doi.org/10.1046/j.1365-2273.2003.00718.x
18. Chen JJ, Shah JL, Harris JP, Bui TT, Schaberg K, Kong CS, et al. Clinical outcomes in elderly patients treated for oral cavity squamous cell carcinoma. Int J Radiat Oncol Biol Phys 2017;98:77583. https://doi.org/10.1016/j.ijrobp.2017.03.017

19. Birim O, Kappetein AP, Bogers AJ. Charlson comorbidity index as a predictor of long-term outcome after surgery for nonsmall cell lung cancer. Eur J Cardiothorac Surg 2005;28:759-62. https://doi. org/10.1016/j.ejcts.2005.06.046

20. Chang CM, Yin WY, Wei CK, Wu CC, Su YC, Yu CH, et al. Adjusted age-adjusted Charlson comorbidity index score as a risk measure of perioperative mortality before cancer surgery. PLoS One 2016;11:e0148076. https://doi.org/10.1371/journal. pone. 0148076

21. Suzuki H, Hanai N, Nishikawa D, Fukuda Y, Koide Y, Kodaira $\mathrm{T}$, et al. The Charlson comorbidity index is a prognostic factor in sinonasal tract squamous cell carcinoma. Jpn J Clin Oncol 2016;46:646-51. https://doi.org/10.1093/jjco/hyw049

22. Charlson ME, Pompei P, Ales KL, MacKenzie CR. A new method of classifying prognostic comorbidity in longitudinal studies: development and validation. J Chronic Dis 1987;40:373-83. https:// doi.org/10.1016/0021-9681(87)90171-8

23. Colinet $\mathrm{B}$, Jacot $\mathrm{W}$, Bertrand $\mathrm{D}$, Lacombe $\mathrm{S}$, Bozonnat $\mathrm{MC}$, Daurès JP, et al.; oncoLR health network. A new simplified comorbidity score as a prognostic factor in non-small-cell lung cancer patients: description and comparison with the Charlson's index. Br J Cancer 2005;93:1098-105. https://doi.org/10.1038/sj.bjc.6602836

24. Volk ML, Hernandez JC, Lok AS, Marrero JA. Modified Charlson comorbidity index for predicting survival after liver transplantation. Liver Transpl 2007;13:1515-20. https://doi.org/10.1002/lt.21172

25. Roseland ME, Pressler ME, Lamerato LE, Krajenta R, Ruterbusch $\mathrm{JJ}$, Booza JC, et al. Racial differences in breast cancer survival in a large urban integrated health system. Cancer 2015;121:3668-75. https://doi.org/10.1002/cncr.29523

26. Bøje CR, Dalton SO, Primdahl H, Kristensen CA, Andersen E, Johansen J, et al. Evaluation of comorbidity in 9388 head and neck cancer patients: a national cohort study from the DAHANCA database. Radiother Oncol 2014;110:91-7. https://doi.org/10.1016/ j.radonc.2013.11.009

27. PACE participants, Audisio RA, Pope D, Ramesh HS, Gennari R, van Leeuwen BL, et al. Shall we operate? Preoperative assessment in elderly cancer patients (PACE) can help. A SIOG surgical task force prospective study. Crit Rev Oncol Hematol 2008;65:156-63. https://doi.org/10.1016/j.critrevonc.2007.11.001

28. Repetto L, Fratino L, Audisio RA, Venturino A, Gianni W, Vercelli $\mathrm{M}$, et al. Comprehensive geriatric assessment adds information to Eastern Cooperative Oncology Group performance status in elderly cancer patients: an Italian Group for Geriatric Oncology Study. J Clin Oncol 2002;20:494-502. https://doi.org/10.1200/ JCO.2002.20.2.494

29. ECOG Performance Status [Internet]. Philadelphia (PA): ECOGACRIN Cancer Research Group [cited 2021 Jan 18]. Available from: https://ecog-acrin.org/resources/ecog-performance-status

30. Leu YS, Chang YF, Lee JC, Liu CJ, Hsiao HT, Chen YJ, et al. Squamous cell carcinoma of the oral cavity in the elderly. Int J Gerontol 2009;3:75-80. https://doi.org/10.1016/S18739598(09)70023-7

31. Ferrari S, Copelli C, Bianchi B, Ferri A, Poli T, Ferri T, et al. Free flaps in elderly patients: outcomes and complications in head and neck reconstruction after oncological resection. J Craniomaxillofac Surg 2013;41:167-71. https://doi.org/10.1016/j.jcms.2012.07.005

32. Tsai CH, Chang KP, Hung SY, Chen WF, Cheng MH, Kao HK. Postoperative morbidity in head and neck cancer ablative surgery followed by microsurgical free tissue transfer in the elderly. Oral Oncol 2012;48:811-6. https://doi.org/10.1016/ j.oraloncology.2012.03.006

33. Peters TT, Langendijk JA, Plaat BE, Wedman J, Roodenburg JL, van Dijk BA, et al. Co-morbidity and treatment outcomes 
of elderly pharyngeal cancer patients: a matched control study. Oral Oncol 2011;47:1159-64. https://doi.org/10.1016/ j.oraloncology.2011.08.004

34. Peters TT, van Dijk BA, Roodenburg JL, van der Laan BF, Halmos GB. Relation between age, comorbidity, and complications in patients undergoing major surgery for head and neck cancer. Ann Surg Oncol 2014;21:963-70. https://doi.org/10.1245/s10434-0133375-x

35. Sarini J, Fournier C, Lefebvre JL, Bonafos G, Van JT, Coche-Dequéant $\mathrm{B}$. Head and neck squamous cell carcinoma in elderly patients: a long-term retrospective review of 273 cases. Arch Otolaryngol Head Neck Surg 2001;127:1089-92. https://doi.org/10.1001/ archotol.127.9.1089

36. Kim YH, Roh JL, Kim SB, Choi SH, Nam SY, Kim SY. Risk factors for competing non-cancer mortality after definitive treatment for advanced-stage head and neck cancer. Oral Dis 2018;24:121725. https://doi.org/10.1111/odi.12904

37. Yang R, Lubek JE, Dyalram D, Liu X, Ord RA. Head and neck cancer surgery in an elderly patient population: a retrospective review. Int J Oral Maxillofac Surg 2014;43:1413-7. https://doi. org/10.1016/j.ijom.2014.08.008

How to cite this article: Lee ST, Kim JW. Factors to consider for surgical in elderly patients with oral cancer. J Korean Assoc Oral Maxillofac Surg 2021;47:388-393. https://doi.org/10.5125/ jkaoms.2021.47.5.388 